\title{
CHEMICAL STABILITY OF PREDNISONE ORAL SUSPENSION AND DRUG SUBSTANCE
}

\author{
CLAUDIO MÜLLER*, GLORIA GODOY, MARTA DE DIEGO.
}

University of Concepción, Pharmacy Department, Pharmacy School, PO Box 237, Concepción, Chile.

(Received: May 5, 2011 - Accepted: December 16, 2010)

\begin{abstract}
An accelerated chemical stability study of Prednisone oral suspension has been performed during 6 months. A stability indicating chromatographic method was developed and validated according to the ICH guidelines by reversed phase using a Chromolith ${ }^{\circledR} \mathrm{C}-18 \mathrm{e}$ monolithic column $4.6 \mathrm{x} 100 \mathrm{~mm}$, water:tetrahydrofuran:methanol $73: 23: 4 \mathrm{v} / \mathrm{v} / \mathrm{v}$ as mobile phase, $\mathrm{UV}$ detection at $243 \mathrm{~nm}$ and $1 \mathrm{~mL} / \mathrm{min}$ flow rate. Prednisolone was used as internal standard. Prednisone drug substance was subjected to forced degradation by acid and basic hydrolysis and oxidation condition, UV-Vis radiation effect, temperature and relative humidity were studied to demonstrate the indicating capability of the chromatographic method. Two and five degradation products were detected at acid and basic forced degradation respectively. No degradation products were detected at the others studied conditions. One degradation product from Prednisone oral suspension was detected during the accelerated chemical stability study. The proposed method was adequate to determine Prednisone drug substance, Prednisone oral suspension and their degradation products. The kinetic parameters of Prednisone oral suspension under the studied conditions are also reported.
\end{abstract}

Keywords: Accelerated Chemical Stability, Prednisone Oral Suspension, Liquid Chromatography.

\section{INTRODUCTION}

Stability is an essential quality attribute for drug products. The rate at which drug products degrade varies dramatically; some products must be used within a day. Other products may, if properly stored and packaged, retain integrity for years. Therefore it's necessary to evaluate the physical, chemical and microbiological changes at the shelf life of the pharmaceutical products to ensure their stability. Associated with those changes, may appear potentially adverse effects, loss of activity, increase in concentration of active, alteration in bioavailability, loss of content uniformity, decline of microbiological status, loss of pharmaceutical elegance and patient acceptability and formation of toxic degradation products. ${ }^{1}$

In recent years, rigorous quality control processes in the pharmaceutical industry has given raise to a growing need for simple, selective and sensitive analytical methods to the study of degradation products as well as impurities; in order to assure the quality of the drug substance or drug product. ${ }^{2}$

Glucocorticoids are widely used to treat various inflammatory and immunological diseases. ${ }^{3}$ Prednisone (figure 1) an old drug but not least, is usually considered as oral glucocorticoid of choice for its anti-inflammatory effect, especially in asthma and allergic children diseases. Also, its immunosuppressant effect is useful to transplanted patients. ${ }^{4}$ Prednisone is a prodrug which is bio transformed to Prednisolone in the liver. ${ }^{5,6}$

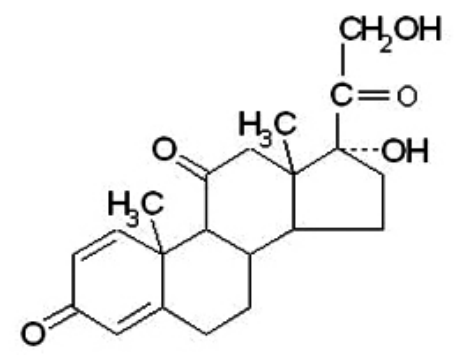

Figure 1 Chemical structure of Prednisone, 17, 21-Dihydroxy pregna-1, 4-diene-3, 11, 20-trione. ${ }^{7}$

In the literature there are some studies related to the determination of Prednisone and other glucocorticoids in biological fluids or biological matrixes $8-10,3,11-16$ dosage forms ${ }^{16-19}$ and stability indicating methods ${ }^{20,21}$ by liquid and gas chromatographic techniques. The official method of the United States
Pharmacopoeia is based on liquid chromatography and it is not a stability indicating method. ${ }^{22}$

The objective of this work was to study and evaluate the chemical behavior of Prednisone oral suspension and drug substance using exaggerated storage conditions throughout an adequate chromatographic stability indicating method. 2,23

This study has been requested by the Analytic Control Department of a local Pharmaceutical Laboratory in order to improve the Prednisone oral suspension $\left(\right.$ Bersen $\left.{ }^{\circledR}\right)$ production process and also to increase its shelf life.

\section{EXPERIMENTAL}

\subsection{Reagents and Standards}

Methanol chromatographic grade Lichrosolv ${ }^{\circledR}$ (Merck, Darmstadt, Germany), tetrahydrofuran chromatographic grade (J.T. Baker, N.J. U.S.A.), sodium hydroxide $0.1 \mathrm{~N}$ and hydrochloride acid $1 \mathrm{~N}$ Tritrisol ${ }^{\circledR}$ (Merck, Darmstadt, Germany), hydrogen peroxide 30\% (DifemPharma ${ }^{\circledR}$, Santiago, Chile). Prednisone base and Prednisolone anhydrous USP standard reference (>98\% purity). Samples Bersen ${ }^{\circ}$ (Prednisone oral suspension $20 \mathrm{mg} / 5 \mathrm{~mL}$ ).

\subsection{Instrumentation}

The chromatographic system consisted of a Merck Hitachi Elite Lachrom chromatograph (Tokyo, Japan) equipped with a quaternary pump series L-2130 a manual injector system, 7725 Rheodyne injection valve (Cotati, CA, U.S.A.), a $5 \mu \mathrm{L}$ loop and a Varian star 800 interface. A Merck Hitachi L-2400 programmable absorbance detector (Tokyo, Japan). The data acquisition software was Varian Star Chromatography Workstation 6.2 (2002). As stationary phase a Chromolith ${ }^{\circledR}$ C-18 monolithic column 4.6 × $100 \mathrm{~mm}$ was employed. The accelerated stability study was carried out in a Binder KBF 115 (Darmstadt, Germany) constant climate chamber.

\subsection{Chromatographic Conditions}

An isocratic elution system composed by water:tetrahydrofuran:methanol $73: 23: 4 \mathrm{v} / \mathrm{v} / \mathrm{v}$ at room temperature, flow $1 \mathrm{~mL} / \mathrm{min}$ and at a wavelength detection $243 \mathrm{~nm}$ was employed.

\subsection{Preparation of Solutions}

\subsubsection{Standard Solutions}

The Prednisone and Prednisolone (internal standard) stock solutions were prepared separately as follow: an accurately weighted amount of standard Prednisone and Prednisolone equivalent about $10 \mathrm{mg}$ were dissolved in methanol until obtain a concentration about $1 \mathrm{mg} / \mathrm{mL}$. This solution was stable for 1 week keeping it at room temperature $21 \pm 2{ }^{\circ} \mathrm{C}$ and for 4 weeks keeping it into freezer at $-5 \pm 2{ }^{\circ} \mathrm{C}$. From these stock solutions, standard solutions 
were prepared and diluted in methanol to the development, optimization and validation of the analytical method.

\subsubsection{Sample Preparation}

Bersen ${ }^{\circledR}(20 \mathrm{mg} / 5 \mathrm{~mL}$ of Prednisone) oral suspension was employed. The experimental procedure was as follows: An accurately weighed portion of 0.3 $\mathrm{g}$ of shaked oral suspension (equivalent to $1 \mathrm{mg}$ of Prednisone) was diluted in $10 \mathrm{~mL}$ of methanol in a $25 \mathrm{~mL}$ volumetric flask. Ultrasound was applied during 5 minutes. Then, $1 \mathrm{~mL}$ of Prednisolone stock solution $(1 \mathrm{mg} / \mathrm{mL})$ was added obtaining a concentration of $40 \mu \mathrm{g} / \mathrm{mL}$ to the internal standard, and diluting with methanol in order to complete volume. The solution was filtered and centrifuged, and the supernatant was injected.

\subsection{Recovery, Repeatability and Reproducibility Study}

To carry out the recovery, repeatability and reproducibility study, simulated pharmaceutical samples of Prednisone oral suspension at 3 added concentration levels, expected to Prednisone respect to its nominal value $20 \mathrm{mg} / 5 \mathrm{~mL}(16,20$ and $24 \mathrm{mg} / 5 \mathrm{~mL})$ were prepared. These simulated oral suspension samples of Prednisone were elaborated mixing all the ingredients according to its elaboration protocol, which was proportioned by the Pharmaceutical Laboratory that produces the drug product Bersen ${ }^{\circledR}$. After that, Prednisone standard was added to achieve every concentration level. These simulated samples were analyzed on five different days to develop the recovery and reproducibility study, and on one day to repeatability study. Thus, the found concentration after the analysis was compared to the added amount of standard Prednisone at the three different levels.

2.6 Determination of the Content of Prednisone in the Samples (Bersen ${ }^{\circledR} 20 \mathrm{mg} / 5 \mathrm{~mL}$ )

The content of Prednisone in the pharmaceutical product was determined according to the sample preparation protocol described at point 2.4.2, for three different batches using the linearity results obtained at the validation of the method procedure.

\subsection{Stability Indicating Capability of the Method}

The chemical stability indicating capability of the HPLC method was demonstrated by forced degradation of Prednisone drug substance at concentration $0.1 \mathrm{mg} / \mathrm{mL}$ under acid (hydrochloride acid $1 \mathrm{~N}, 1000 \mu \mathrm{L}$ ), basic (sodium hydroxide $0.1 \mathrm{~N}, 250 \mu \mathrm{L}$ ) and oxidation (hydrogen peroxide $30 \%, 250$ $\mu \mathrm{L}$ ) conditions, all these conditions at 55 Celsius degrees during 1 hour. In parallel, the UV-Vis radiation decomposition (UV $365 \mathrm{~nm}$, Vis $380-780 \mathrm{~nm}$ ) and the temperature effect ( 40 Celsius degrees and 40 Celsius degrees and 75 $\%$ R.H.) were evaluated for Prednisone drug substance in solution and solid state during 1 week.

\subsection{Chemical Stability Study}

Prednisone oral suspension was subjected to an accelerated stability study according to the ICH guidelines for drug products at $40 \pm 2$ Celsius degrees and $75 \pm 5 \%$ R.H. during 6 months in an environmental simulation chamber. ${ }^{24}$ The samples were packaged into their primary amber glass and plastic packages and evaluated at different time intervals.

\subsection{Determination of Kinetic Parameters}

The kinetic parameters were determinated according to the plot obtained from the accelerated stability study (Remaining percentage of Prednisone oral suspension against the time).

\section{RESULTS AND DISCUSSION}

3.1 Development and Optimization of the Chromatographic Method

To optimize the chromatographic method, three mobiles phases at different rates flow and two stationeries phases were tested using a standard solution of Prednisone at concentration $0.1 \mathrm{mg} / \mathrm{mL}$. Column 1 consisted in a conventional Kromasil ${ }^{\circledR} \mathrm{C}-18 \mathrm{e} 4.6 \times 150 \mathrm{~mm} 5 \mu \mathrm{m}$, and column 2, a Chromolith ${ }^{\circledR}$ C-18e monolithic $4.6 \times 100 \mathrm{~mm}$. The mobile phase 1 consisted in acetonitrile:water 60:40 v/v, mobile phase 2 methanol:water 70:30 v/v and mobile phase 3 water:tetrahydrofuran:methanol 73:23:4 v/v/v. The efficiency of the chromatographic method is expressed in terms of Height Equivalent Plate Theory (HEPT) and tailing factor; tables 1, 2 and 3 show the obtained data.
Table 1: Mobile phase 1, acetonitrile:water $60: 40 \mathrm{v} / \mathrm{v}$ tested in both columns during the development of the method.

\begin{tabular}{|c|c|c|c|c|c|c|}
\hline & \multicolumn{2}{|c|}{ Conventional Column (1) } & \multicolumn{3}{|c|}{ Monolithic Column (2) } \\
\hline $\begin{array}{c}\text { Mobile } \\
\text { phase } \\
1, \text { flow } \\
\text { rate } \\
(\mathrm{mL} / \\
\text { min) }\end{array}$ & $\begin{array}{c}\text { Prednisone } \\
\text { retention } \\
\text { time } \\
(\mathrm{min})\end{array}$ & $\begin{array}{c}\text { HEPT } \\
\times 10^{-3} \\
(\mathrm{~cm})\end{array}$ & $\begin{array}{c}\text { Tail- } \\
\text { ing } \\
\text { factor }\end{array}$ & $\begin{array}{c}\text { Pred- } \\
\text { nisone } \\
\text { reten- } \\
\text { tion } \\
\text { time } \\
(\mathrm{min})\end{array}$ & $\begin{array}{c}\text { HEPT } \\
\times 10^{-3} \\
(\mathrm{~cm})\end{array}$ & $\begin{array}{c}\text { Tailing } \\
\text { factor }\end{array}$ \\
\hline 0.25 & 15.23 & 4.50 & 2.10 & ---- & ---- & ---- \\
\hline 0.50 & 13.59 & 4.30 & 2.00 & 8.23 & 3.90 & 1.80 \\
\hline 0.75 & 11.04 & 3.90 & 1.80 & 6.89 & 3.80 & 1.80 \\
\hline 1.00 & 8.51 & 3.90 & 1.50 & 4.52 & 3.30 & 1.40 \\
\hline 1.25 & 6.71 & 4.10 & 1.50 & 2.39 & 3.50 & 1.40 \\
\hline 1.50 & ---- & ---- & ---- & 0.93 & 3.50 & 1.30 \\
\hline 1.75 & ---- & ---- & ---- & ---- & ---- & ---- \\
\hline 2.00 & ---- & ---- & ---- & ---- & ---- & ---- \\
\hline
\end{tabular}

Table 2: Mobile phase 2, methanol:water 70:30 v/v tested in both columns during the development of the method.

\begin{tabular}{|c|c|c|c|c|c|c|}
\hline & \multicolumn{2}{|c|}{ Conventional Column (1) } & \multicolumn{3}{|c|}{ Monolithic Column (2) } \\
\hline $\begin{array}{c}\text { Mobile } \\
\text { phase 2, } \\
\text { flow rate } \\
(\mathrm{mL} / \\
\text { min) }\end{array}$ & $\begin{array}{c}\text { Prednisone } \\
\text { retention } \\
\text { time (min) }\end{array}$ & $\begin{array}{c}\text { HEPT } \\
\text { x 10-3 } \\
(\mathrm{cm})\end{array}$ & $\begin{array}{c}\text { Tail- } \\
\text { ing } \\
\text { factor }\end{array}$ & $\begin{array}{c}\text { Pred- } \\
\text { nisone } \\
\text { reten- } \\
\text { tion } \\
\text { time } \\
(\mathrm{min})\end{array}$ & $\begin{array}{c}\text { HEPT } \\
\text { x 10-3 } \\
(\mathrm{cm})\end{array}$ & $\begin{array}{c}\text { Tailing } \\
\text { factor }\end{array}$ \\
\hline 0.25 & 16.84 & 4.90 & 2.30 & ---- & ---- & ---- \\
\hline 0.50 & 14.58 & 4.70 & 2.10 & 8.99 & 3.80 & 2.00 \\
\hline 0.75 & 12.30 & 4.40 & 2.00 & 7.03 & 3.70 & 1.90 \\
\hline 1.00 & 9.85 & 4.20 & 1.80 & 5.57 & 3.50 & 1.90 \\
\hline 1.25 & 7.46 & 4.20 & 1.80 & 4.12 & 3.40 & 1.80 \\
\hline 1.50 & ---- & ---- & ---- & 2.90 & 3.40 & 1.70 \\
\hline 1.75 & ---- & ---- & ---- & 2.08 & 3.20 & 1.70 \\
\hline 2.00 & ---- & ---- & ---- & 1.43 & 3.30 & 1.50 \\
\hline
\end{tabular}

Table 3: Mobile phase 3, water:tetrahydrofuran:methanol 73:23:4 v/v/v tested in both columns during the development of the method.

\begin{tabular}{|c|c|c|c|c|c|c|}
\hline & \multicolumn{2}{|c|}{ Conventional Column (1) } & \multicolumn{2}{|c|}{ Monolithic Column (2) } \\
\hline $\begin{array}{c}\text { Mobile } \\
\text { phase 3, } \\
\text { flow rate } \\
\text { (mL/ } \\
\text { min) }\end{array}$ & $\begin{array}{c}\text { Prednisone } \\
\text { retention } \\
\text { time (min) }\end{array}$ & $\begin{array}{c}\text { HEPT } \\
\text { X } \\
10^{-2} \\
(\mathrm{~cm})\end{array}$ & $\begin{array}{c}\text { Tail- } \\
\text { ing } \\
\text { factor }\end{array}$ & $\begin{array}{c}\text { Pred- } \\
\text { nisone } \\
\text { reten- } \\
\text { tion } \\
\text { time } \\
(\mathrm{min})\end{array}$ & $\begin{array}{c}\text { HEPT } \\
\text { x 10-3 } \\
(\mathrm{cm})\end{array}$ & $\begin{array}{c}\text { Tailing } \\
\text { factor }\end{array}$ \\
\hline 0.25 & 23.70 & 3.80 & 2.10 & ---- & ---- & ---- \\
\hline 0.50 & 11.95 & 3.00 & 2.00 & 7.62 & 2.00 & 2.00 \\
\hline 0.75 & 8.01 & 3.50 & 1.90 & 5.08 & 2.50 & 1.90 \\
\hline 1.00 & 5.98 & 4.30 & 1.60 & 3.82 & 0.60 & 1.60 \\
\hline 1.25 & 4.76 & 4.70 & 1.50 & 3.06 & 0.70 & 1.60 \\
\hline 1.50 & ---- & ---- & ---- & 2.55 & 5.40 & 1.50 \\
\hline 1.75 & ---- & ---- & ---- & 2.01 & 3.50 & 1.50 \\
\hline 2.00 & ---- & ---- & ---- & 1.93 & 3.00 & 1.60 \\
\hline
\end{tabular}

The monolithic column (2) and mobile phase 3 at $1 \mathrm{~mL} / \mathrm{min}$ flow rate were the most efficient and adequate to determination of Prednisone drug substance and drug product (oral suspension), considering the HEPT and tailing factor, two parameters of the chromatographic efficiency. ${ }^{22}$

\subsection{Validation of Methodology}

The experimental methodology was validated according to the $\mathrm{ICH}$ guidelines for validation of analytical procedures. ${ }^{25}$

\subsubsection{Linearity}

The calibration curve was drawn in the concentration range from 20 to 60 
$\mu \mathrm{g} / \mathrm{mL}$, five different concentrations were employed (20, 30, 40, 50 and $60 \mu \mathrm{g} /$ $\mathrm{mL}$ ), and each standard solution was injected 5 times. The ratio of peak areas between Prednisone and internal standard Prednisolone was plotted against the concentration of Prednisone, the linear regression equation was $\mathrm{y}=0.0276 \mathrm{x}-$ $0.0028\left(r^{2}=0.9981\right)$.

\subsubsection{Repeatability and Reproducibility Study}

The intraday precision was determined with the simulated pharmaceutical samples of Prednisone oral suspension described on point 2.5 on the same day. The interday precision was determined for the same simulated pharmaceutical samples by comparison of the analytical results on five different days. Table 4 shows the results in terms of the relative standard deviation (RSD).

Table 4: Repeatability and reproducibility determined during the validation of the method.

\begin{tabular}{|c|c|c|}
\hline \multirow{2}{*}{$\begin{array}{c}\text { Added concentration } \\
\text { of Prednisone } \\
(\mathrm{mg} / \mathrm{mL})\end{array}$} & intra-day $^{\mathrm{a}}$ & inter-day $^{\mathrm{b}}$ \\
\cline { 2 - 3 } & 1.59 & \\
\hline 3.20 & 1.46 & 1.89 \\
\hline 4.00 & 1.15 & 1.96 \\
\hline 4.20 & \multicolumn{2}{|c|}{ Relative Standard Deviation (\%) } \\
\hline
\end{tabular}

a: Analyzed on the same day $(n=3)$

$\mathrm{b}$ : Analyzed on five different days $(\mathrm{n}=15)$

The proposed analytical method revealed a suitable repeatability and reproducibility, this according to validation procedures for pharmaceutical products (Relative Standard Deviation less than $2 \%$ ). ${ }^{22}$

\subsubsection{Recovery Study}

The recovery study was evaluated in terms of recovery percentage of Prednisone based on the same simulated pharmaceutical samples described on point 2.5 on five different days. Table 5 shows these results.

Table 5: Recovery percentage determined during the validation of the method.

\begin{tabular}{|c|c|c|}
\hline $\begin{array}{c}\text { Added percentage of } \\
\text { Prednisone } \\
(\%)\end{array}$ & $\begin{array}{c}\text { Recovery } \\
\text { percentage } \\
(\%)^{\mathrm{a}}\end{array}$ & $\begin{array}{c}\text { Relative Standard } \\
\text { Deviation } \\
(\%)\end{array}$ \\
\hline 80.00 & $100.90 \pm 1.60$ & 1.28 \\
\hline 100.00 & $102.60 \pm 1.90$ & 1.93 \\
\hline 120.00 & $99.80 \pm 0.90$ & 1.27 \\
\hline a: Mean \pm SD $(\mathrm{n}=15)$ & \multicolumn{2}{|l}{}
\end{tabular}

\subsubsection{Detection and Quantitation Limit}

Detection limit was $0.03 \mu \mathrm{g} / \mathrm{mL}$ and Quantitation limit was $0.09 \mu \mathrm{g} / \mathrm{mL}$, determined according to standard deviation of the response and the slope on the calibration curve.

\subsubsection{Specificity}

The specificity of the method was evaluated through possible interferences caused by oral suspension ingredients. Figure 2 shows a chromatogram obtained from an oral suspension solution of Bersen $\circledR^{\text {. }}$

3.3 Determination of the Content of Prednisone in the Oral Suspension

Table 6 shows the results obtained from the determination of Prednisone in pharmaceutical samples Bersen ${ }^{\circledR} 20 \mathrm{mg} / 5 \mathrm{~mL}$.

Even though, Prednisone oral suspension does not exist in The United States Pharmacopeia as dosage form, concentration of Prednisone in the analyzed samples was within the acceptable range; this is according to the official method of analysis (90 to $110 \%)^{22}$ for the others Prednisone dosage forms.

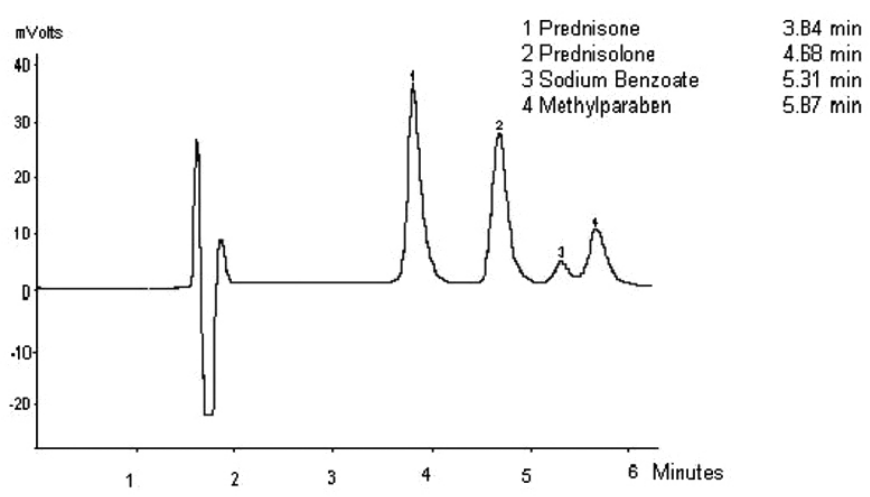

Figure 2: Representative chromatogram from a sample solution of the oral suspension, Prednisone (1), internal standard Prednisolone (2) at concentration $40 \mu \mathrm{g} / \mathrm{mL}$, soluble ingredients Sodium benzoate (3) and Methylparaben (4). Chromatographic conditions: monolithic RP-18e column $100 \times 4.6 \mathrm{~mm}$, mobile phase water:tetrahydrofuran:methanol 73:23:4 v/v/v, flow $1.0 \mathrm{~mL} / \mathrm{min}$ and detection at $243 \mathrm{~nm}$.

Table 6: Content of Prednisone in the oral suspension samples.

\begin{tabular}{|c|c|c|}
\hline Batch & $\begin{array}{c}\text { Percentage of Prednisone } \\
(\%)\end{array}$ & $\begin{array}{c}\text { Relative Standard } \\
\text { Deviation (\%) }\end{array}$ \\
\hline 1 & $102.46 \pm 1.62$ & 1.58 \\
\hline 2 & $100.93 \pm 0.86$ & 0.85 \\
\hline 3 & $101.15 \pm 1.48$ & 1.46 \\
\hline *Average \pm SD $(\mathrm{n}=3)$ &
\end{tabular}

\subsection{Stability Indicating Capability of the Method}

Figures 3 and 4 show that there is not interference between Prednisone and its degradation products obtained by forced degradation at acid and basic conditions.

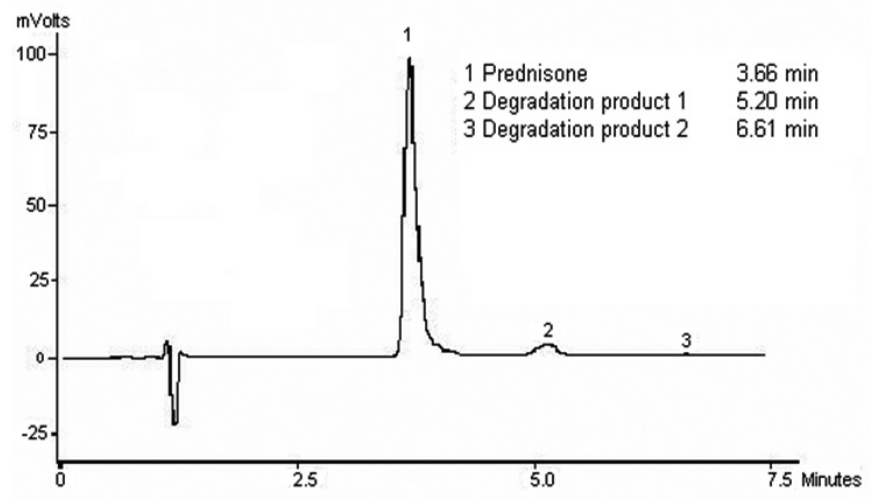

Figure 3: Representative chromatogram from forced acid degradation Prednisone drug substance (HCl 1N, $1000 \mu \mathrm{L}, \mathrm{pH} 2,55$ Celsius degrees during 1 hour), Prednisone $0.1 \mathrm{mg} / \mathrm{mL}$ (1), Degradation product 1 (2) and Degradation product 2 (3). Chromatographic conditions: monolithic RP-18e column $100 \mathrm{x}$ $4.6 \mathrm{~mm}$, mobile phase water:tetrahydrofuran:methanol 73:23:4 v/v/v, flow 1.0 $\mathrm{mL} / \mathrm{min}$, detection at $243 \mathrm{~nm}$.

According to the results, Prednisone drug substance is more susceptible to alkaline forced degradation (five degradation products). An important condition to be considered during the drug product's manufacturing process, in this case an oral suspension.

No degradation products were detected at oxidation condition, UV-Vis radiation and temperature exposure for Prednisone drug substance in solution and solid state respectively. 


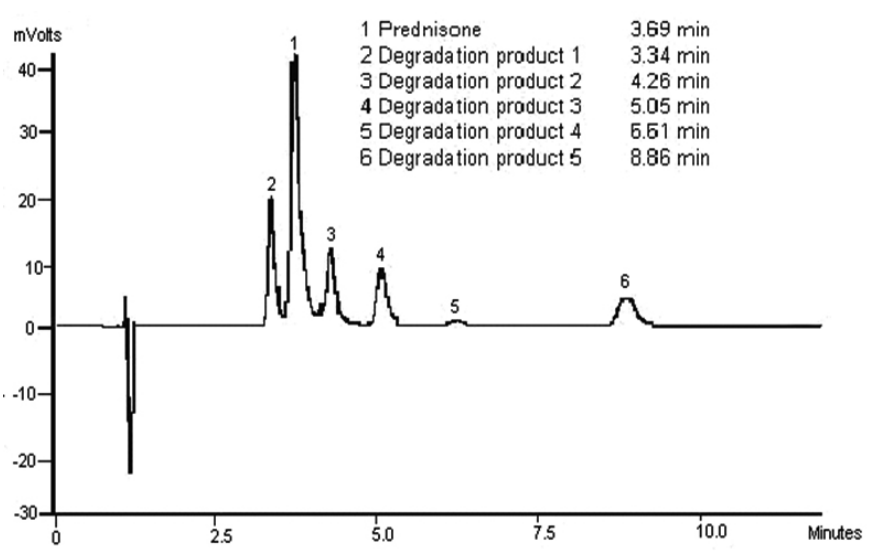

Figure 4: Representative chromatogram from forced basic degradation Prednisone drug substance $(\mathrm{NaOH} 0.1 \mathrm{~N}, 250 \mu \mathrm{L}, \mathrm{pH} 10,55$ Celsius degrees, during 1 hour). Prednisone $0.1 \mathrm{mg} / \mathrm{mL}$ (1), Degradation product 1 (2), Degradation product 2 (3), Degradation product 3 (4), Degradation product 4 (5) and Degradation product 5 (6). Chromatographic conditions: monolithic RP-18e column $100 \times 4.6 \mathrm{~mm}$, mobile phase water:tetrahydrofuran:methanol 73:23:4 v/v/v, flow $1.0 \mathrm{~mL} / \mathrm{min}$, detection at $243 \mathrm{~nm}$.

\subsection{Chemical Stability Study}

Table 7 shows the results obtained in the accelerated degradation study of Prednisone oral suspension Bersen ${ }^{\circledR}$ during 6 months at $40 \pm 2$ Celsius degrees and $75 \pm 5 \%$ R.H.

Table 7: Remaining percentage of Prednisone in the pharmaceutical samples.

\begin{tabular}{|c|c|c|}
\hline & \multicolumn{2}{|c|}{ Remaining percentage (\%) $^{\text {a }}$} \\
\hline Day & Glass package $^{\mathrm{b}}$ & Plastic Package ${ }^{\mathrm{c}}$ \\
\hline 0 & 100.00 & 100.00 \\
\hline 12 & 99.85 & 99.71 \\
\hline 26 & 99.06 & 99.14 \\
\hline 40 & 98.16 & 98.11 \\
\hline 54 & 97.60 & 97.34 \\
\hline 68 & 97.09 & 96.77 \\
\hline 82 & 96.12 & 96.03 \\
\hline 97 & 95.37 & 95.40 \\
\hline 135 & 94.40 & 94.39 \\
\hline 180 & 93.75 & 93.39 \\
\hline $\mathrm{n}=2$ & & \\
\hline
\end{tabular}

a: Average of three different batches

b: Neutral amber glass

c: Amber High Density Polyethylene

After 180 days of accelerated stability study, the remaining percentage of Prednisone was lower than $95 \%$ and only degradation product 5 (see basic degradation of Prednisone on point 3.4, figure 4) was detected in both types of packages. Figure 5 describes this situation.

\subsection{Determination of Kinetic Parameters}

The degradation of Prednisone in both cases (glass and plastic package), followed a zero order of reaction according to the plot obtained from the accelerated stability study. Table 8 shows the kinetic parameters under the exaggerated studied conditions.

Table 8: Kinetic Parameters of Prednisone in the oral suspension.

\begin{tabular}{|c|c|c|c|}
\hline & $\begin{array}{c}\text { Degradation } \\
\text { constant k x 10-7 } \\
\left(\text { (mol L }^{-1} \text { day }^{-1} \text { ) }\right.\end{array}$ & $\begin{array}{c}\text { Shelf life } \\
\text { (months) }\end{array}$ & $\begin{array}{c}\text { Efficacy } \\
\text { period t } \\
\text { (months) }\end{array}$ \\
\hline Glass package $^{\text {a }}$ & 1.72 & 46.00 & 8.00 \\
\hline Plastic package $^{\text {a }}$ & 1.70 & 46.00 & 8.00 \\
\hline
\end{tabular}

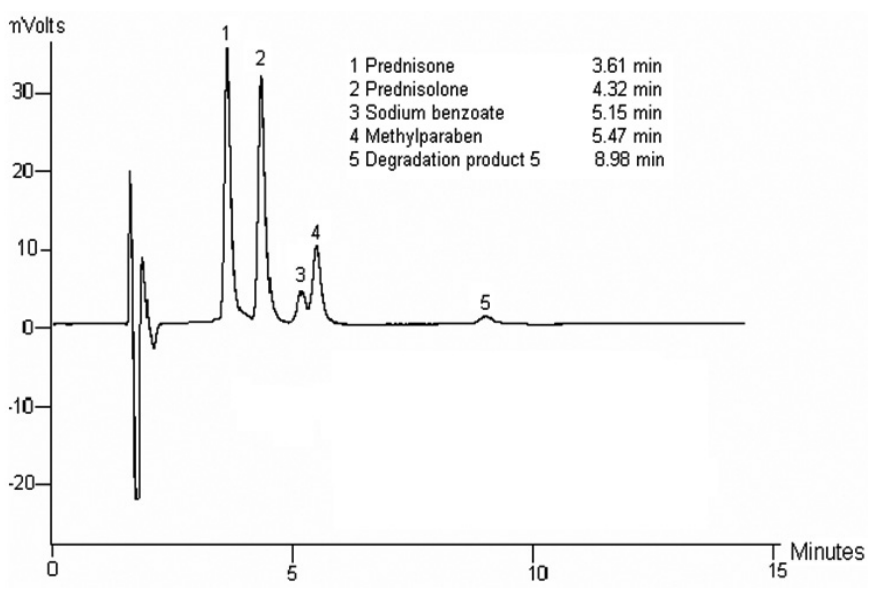

Figure 5: Representative chromatogram from the oral suspension Bersen ${ }^{\circledR}$ during the accelerated stability study (day 180) in amber glass and plastic package. Prednisone (1), Prednisolone (2), Sodium benzoate (3), Methylparaben (4) and Degradation product 5 (5). Chromatographic conditions: monolithic RP-18e column $100 \times 4.6 \mathrm{~mm}$, mobile phase water:tetrahydrofuran:methanol $73: 23: 4 \mathrm{v} / \mathrm{v} / \mathrm{v}$, flow $1.0 \mathrm{~mL} / \mathrm{min}$, detection at $243 \mathrm{~nm}$.

The manufacturing laboratory should employ the most convenient type of package in the elaboration process because there was not difference between glass and plastic package in terms of degradation constant values of Prednisone in oral suspension (Bersen ${ }^{\circledR}$ ) and the others kinetic parameters.

\section{CONCLUSIONS}

$>\quad$ A liquid chromatographic method to determine Prednisone drug substance and oral suspension was developed.

$>\quad$ The developed method was validated satisfactorily in terms of linearity, repeatability and reproducibility, recovery percentage, detection limit, quantitation limit and specificity.

$>\quad$ The developed and validated liquid chromatographic method demonstrated to be indicator of chemical stability for Prednisone drug substance and Prednisone drug product (oral suspension).

$>\quad$ An accelerated stability study was performed to Prednisone oral suspension during 6 months.

$>\quad$ One degradation product of Prednisone oral suspension was detected during the accelerated stability study.

\section{REFERENCES}

1. J. Carstensen, C. Rhodes, Drug Stability Principles and Practices, $3^{\text {rd }}$ ed.,Taylor \& Francis: New York, 2000.

2. S. Brain-Isasi, C. Requena, A. Álvarez-Lueje, J. Chil. Chem. Soc. 53, 1684, (2008).

3. L. Amendola, F. Garribba, F. Botrè, Anal. Chim. Acta 489, 233, (2003).

4. O. Nozaki, J. of Chromatogr A 935, 267, (2001).

5. G. Mc Evoy, AHFS Drug Information, American Society of Health System Pharmacists, Wisconsin, 2006.

6. S. Sweetman, Martindale The complete drug reference, $3^{\text {rd }}$ ed., Pharmaceutical Press, London, 2002.

7. M. Windholz, THE MERCK INDEX AN ENCYCLOPEDIA OF CHEMICALS, DRUGS AND BIOLOGICALS, $10^{\text {th }}$ ed., Merck \& CO., Inc. New Jersey, 1983.

8. J. Andersen, L. Hansen, M. Pedersen, Anal. Chim. Acta 617, 216, (2008).

9. R. DiFrancesco, V. Frerichs, J. Donnelly, C. Hagler, J. Hochreiter, K. Tornatore, J. of Chromatogr. B 859, 42, (2007).

10. V. Frerichs, K. Tornatore, J. of Chromatogr. B 802, 329, (2004).

11. F. Bévalot, Y. Gaillard, M. Lhermitte, G. Pépin, J. of Chromatogr B 740, 227, (2000).

12. N. Shibata, T. Hayakawa, K. Takada, N. Hoshino, T. Monouchi, A. Yamaji, J. of Chromatogr B 706, 191, (1998). 
13. A. Santos-Montes, R. Gonzalo-Lumbreras, R. Izquierdo-Hornillo, J. of Chromatogr. B 673, 27, (1995).

14. P. Volin, J. of Chromatogr. B 671, 319, (1995).

15. P. Volin, J. of Chromatogr. B 666, 347, (1995).

16. R. Taylor, S. Grebe, R. Singh, Clin. Chem. 50, 2345, (2004).

17. M. Ali, M. Ghori, A. Saeed, J. of Chromatogr. Sci., 40, 429, (2002).

18. K. Liu, S. Chen, S. Wu, H. Kou, H. Wu, J. of Chromatogr. A 676, 455, (1994).

19. M. Santoro, E. Govato, E. Hackmann, Anal. Lett. 26, 925, (1993).

20. K. Yamamura, J. Yamada, J. of Chromatogr. A 331, 383, (1985).

21. P. Williams, F. Biehl, J. of Pharm. Sci. 70, 530, (1981).

22. FARMACOPEA DE LOS ESTADOS UNIDOS DE AMERICA, FORMULARIO NACIONAL USP 29/NF24, The UNITED STATES PHARMACOPEIAL CONVECTION, INC. Rockville, 2005.
23. M. Gulam, A. Adnan, A. Farhan, K. Zeenat, S. Faiyaz, T. Sushma, J. Chil. Chem. Soc. 55, 184, (2010).

24. International Conference on Harmonisation of Technical Requirement for Designation of Pharmaceuticals for Human Use, ICH Harmonised Tripartite Guideline Stability Testing of New Drug Substances and Products, 2003.

25. International Conference on Harmonisation of Technical Requirement for Designation of Pharmaceuticals for Human Use, ICH Harmonised Tripartite Guideline, Validation of Analytical Procedures, Text and Methodology, 1996. 